\title{
Seasonal Variation in Leaf Growth and Antioxidant Content of Moringa oleifera Cultivated at Buenos Aires, Argentina
}

\author{
Miriam Elisabet Arena* and Silvia Radice \\ CONICET - Facultad de Agronomía y Ciencias Agroalimentarias, Universidad de Morón. Machado 914. B1708EOH, Morón, \\ Buenos Aires, Argentina \\ *For correspondence: miriamearena@gmail.com
}

\begin{abstract}
The properties and applications of Moringa oleifera are so vast that it is called the "miracle tree". The objective of this work is to study the seasonal variations in the leaf antioxidant content and the scavenging activity on DPPH radicals in concordance with its growth on $M$. oleifera plants of two seed origin, Commercial (C, seeds that were obtained from a market) and Bolivia (B, seeds that were obtained from a commercial forest of Santa Cruz de la Sierra, Bolivia); the experiment was conducted at Buenos Aires, Argentina. Significant differences were found on leaf growth, antioxidant content and DPPH activity along the growing season. The lower leaf dry weight as percentage of fresh weight, higher specific leaf area, higher relative growth rate and lower phenol content on B leaves than $\mathrm{C}$ leaves could indicate that B plants are geared for a higher productivity rate of resource acquisition than $\mathrm{C}$ plants. Specific leaf area, leaf dry weight as percentage of fresh weight, phenol content and activity of DPPH radicals on leaf extracts were significantly correlated, which could be used on productivity estimation and nutraceutical valuation. The phenol content and activity of DPPH radicals of leaf extracts of B and C origins indicate that the leaves of the plants growing in the described conditions are of noteworthy value. These are the first antecedents for $M$. oleifera growing at Buenos Aires, Argentina, allowing to preliminary consider this area as one of the southernmost zone. (C) 2016 Friends Science Publishers
\end{abstract}

Keywords: Specific leaf area; Dry matter content; Phenols; DPPH activity

\section{Introduction}

Moringa oleifera is a tree belonging to the Moringaceae family. It is indigenous of south Asia, mainly in Himalayan foothills and India (Parrotta, 1993). At present, M. oleifera is cultivated in many countries in tropical and subtropical regions of Africa, Southeast Asia and South America (Ganatra Tejas et al., 2012). No experimental studies exist today that can provide data of the possibilities of cultivation of this species in Argentina. However, Falasca and Bernabé (2008) made a careful study to delimit the potential agroecological zone of culture of $M$. oleifera in this country. Some years ago there were commercial plantations in the NW of Argentina (Oran, Salta). Oil produced from the seeds was exported only for cosmetic use. Two agribusinesses developed near Santa Cruz de la Sierra in Bolivia had the same purpose (personal comments).

The properties and applications of $M$. oleifera are so vast that it is called the "miracle tree". Among the most common uses, $M$. oleifera is employed as fuel, in the pharmacological industry, in human nutrition and animal fodder. Seeds are used in water purification and for oil extraction for multipurpose (Palafox et al., 2012). One use of this oil is the production of biofuels as biodiesel (Rashid et al., 2008), but it is also employed as cooking oil and in pharmacopoeia and cosmetology for its medicinal properties (Delaveau and Boiteau, 1980; Basra et al., 2015). Moringa oil unsaponifiables contain copious amounts of tocopherols and sterols (Anwar et al., 2006).

The potential uses of this species in medicine are as: cardiac and circulatory stimulants, antitumor, antipyretic, antiepileptic, anti-inflammatory, antiulcer, antispasmodic, diuretic antihypertensive, cholesterol lowering, antioxidant, antidiabetic, hepatic-protective, antibacterial and antifungal activities (Arora et al., 2013). In addition, endophytic fungi isolated from leaves of $M$. oleifera are producers of bioactive compounds that can be used in various fields such as medicine, agriculture, environment, etc. (Dhanalakshmi et al., 2013). In human nutrition, the European Commission introduced this species as "novel food" due to the importance that it has acquired in recent years. In effect, it has been shown that Moringa leaves are a source of energy, nutrients, proteins and minerals such as: $\mathrm{Ca}, \mathrm{K}, \mathrm{Mg}, \mathrm{P}, \mathrm{Fe}$ and Zn (Yameogo et al., 2011). Moringa leaves are rich in vitamin $\mathrm{A}$ and $\mathrm{C}$ and it is considered useful in scurvy and catarrhal affections (Singh et al., 2012). Also, leaves are rich in ascorbic acid, amino acids, sterols, isoquertecil glucoside, carotenes, rhamentin, kaempferol, kaempferitrin 
(Nair and Sankaras, 1962) and polyphenols with antioxidant properties (Atawodi et al., 2010; Leone et al., 2015a, b; Sankhalkar and Vernekar, 2016). Moreover, Moringa leaves contain further hypoglycemic compounds (Tende et al., 2011).

However, little is known about the seasonal variation in the antioxidant content and the antioxidant activity together with the growth of $M$. oleifera leaves. Therefore, the present study investigates the changes along the growing season in the antioxidant and total phenol content with the scavenging activity on DPPH radicals in concordance with the growth of $M$. oleifera leaves from plants of two seed origins; the experiment was conducted at Buenos Aires, Argentina.

\section{Materials and Methods}

\section{Plant Material and Sampling}

Moringa oleifera plants (one year old) were obtained through germinated seeds from two origins: Commercial $(\mathrm{C}$, seeds that were obtained from a market) and Bolivia (B, seeds that were obtained from a commercial forest of Santa Cruz de la Sierra, Bolivia). The seeds were germinated with a substrate soil: perlite $(1: 1)$. The plants $(n=100$ for each origin) were growing in plastic pots $\left(50 \mathrm{dm}^{3}\right)$ filled with soil: perlite (1:1) (Salinas, 2013) in the greenhouse of the Moreno Experimental field at Morón University (34 39' SL, 58 47' WL, $19 \mathrm{~m}$ a.s.l) until October 2013, when this experiment started. The mean air temperature from September 2013 to January 2014 (Fig. 1) was registered with a Meteorological Station placed in the experimental field.

Selected leaves from the middle position of the main trunk (1 per plant) were harvested once a month from October 2013 to January 2014.

\section{Leaf Growth}

For each leaf and each day of harvest $(n=10)$ fresh and dry weight of leaves and dry weight as percentage of fresh weight were recorded. Also, leaf area, leaf perimeter, specific leaf area (leaf area/leaf dry weight) and leaflet number were analysed. UTHSCSA Image Tool software (San Antonio, Texas, USA) was applied on pictures taken on leaves to measure biometric parameters.

\section{Phenol Content}

The methodology employed for the extraction and determination of the phenolic compounds was described by Makkar et al. (1993). Briefly, $0.5 \mathrm{~g}$ of dry leaves (three leaves for each sample) were extracted with $(80 \%)$ methanol $(5.0 \mathrm{~mL})$ in darkness and at $7^{\circ} \mathrm{C}$ for $24 \mathrm{~h}(n=3)$. Aliquots $(25.0 \mu \mathrm{L})$ of the methanolic extracts were transferred to glass tubes and the volume was adjusted to $500.0 \mu \mathrm{L}$ with deionized water. Then, $250.0 \mu \mathrm{L}$ of $50 \%$ Folin-Ciocalteu reagent and $1.25 \mathrm{~mL}$ of $(20 \%)$ aqueous sodium carbonate solution were added. After standing for $40 \mathrm{~min}$ at $24^{\circ} \mathrm{C}$, the absorbance of the resulting colored solutions were measured against a blank at $725 \mathrm{~nm}$ using a Shimadzu 1203 UV Vis spectrophotometer. The phenol content was obtained from the calibration curve prepared using tannic acids standard, and expressed as mg tannic acid equivalents/1 g dry weight.

\section{Preparation of Extracts from Leaf and Extraction Yield}

Dried leaves $(0.5 \mathrm{~g}$ obtained from three leaves for each sample) were extracted with $5.0 \mathrm{~mL}$ of methanol at 24 으 $\mathrm{C}$ for $24 \mathrm{~h}$ with continuous stirring. The residue was later extracted twice with additional volumes of $5.0 \mathrm{~mL}$ methanol for $48 \mathrm{~h}$, and the three extracts were combined. The extraction yield was determined gravimetrically from the methanolic extracts $(n=3)$ carried out in triplicate (Arena et al., 2012). The extracts were then used to determine the DPPH scavenging activity.

\section{Scavenging Activity on DPPH Radicals}

Each methanolic extract $(0.0$ to $0.5 \mathrm{mg} / \mathrm{mL})$ in methanol $(2.0 \mathrm{~mL})$ was mixed with $0.25 \mathrm{~mL}$ of a methanolic solution containing DPPH radicals, resulting in a final concentration of $0.1 \mathrm{mM}$ DPPH. The mixture was shaken vigorously and allowed to stand in darkness for $30 \mathrm{~min}$. The absorbance was then measured at $517 \mathrm{~nm}$ against a blank in a Shimadzu 1203 UV Vis spectrophotometer (modified method of Shimada et al., 1992). A low absorbance value for the reaction mixture indicates high free radical scavenging activity. The capability of methanolic extracts to scavenge DPPH radicals was calculated using the following equation: DPPH scavenging effect $(\%)=\left[\left(\mathrm{A}_{\text {blank }}-\mathrm{A}_{\text {sample }} / \mathrm{A}_{\text {blank }}\right) \times 100\right]$, where A blank is the absorbance of the control reaction (containing all reagents except the test compound) and A sample is the absorbance of the reaction mixture for the compound scavenging effect. The values for the DPPH scavenging effect were calculated for all methanolic extracts under study.

\section{Statistical Analysis}

Data were analyzed statistically by two and three-way analysis of variance (ANOVA), and means were then separated using the Tukey multiple range test at $p \leq 0.05$. Linear coefficient correlations were performed between some pairs of variables.

\section{Results}

Fresh and dry weight of leaf significantly increased along the growing season being maxima on January (5.7 and 1.3 $\mathrm{g}$, respectively) (Table 1). Leaf dry weight as percentage of 
Table 1: $M$. oleifera leaf growth; Mean values of ANOVA considering the month and the origin as main factors, and the fresh weight $(\mathrm{FW})(\mathrm{g})$, dry weight $(\mathrm{DW})(\mathrm{g})$, dry weight as percentage of fresh weight (DWP) $(\%)$, area (A) $\left(\mathrm{cm}^{2}\right)$, perimeter $(\mathrm{P})(\mathrm{cm})$, specific leaf area $(\mathrm{SLA})\left(\mathrm{cm}^{2} / \mathrm{g}\right)$ and leaflet number $(\mathrm{LN})$ as dependent variables

\begin{tabular}{llllllll}
\hline Main factor & FW & DW & DWP & A & P & SLA & LN \\
\hline Month & & & & & & & \\
October & $0.57 \mathrm{c}$ & $0.12 \mathrm{~d}$ & $20.69 \mathrm{~b}$ & $25.62 \mathrm{~b}$ & $98.73 \mathrm{c}$ & $220.30 \mathrm{~b}$ & $30.65 \mathrm{c}$ \\
November & $3.18 \mathrm{~b}$ & $0.50 \mathrm{c}$ & $15.58 \mathrm{c}$ & $185.85 \mathrm{ab}$ & $480.60 \mathrm{~b}$ & $403.16 \mathrm{a}$ & $41.20 \mathrm{c}$ \\
December & $4.41 \mathrm{ab}$ & $0.97 \mathrm{~b}$ & $22.07 \mathrm{a}$ & $188.61 \mathrm{ab}$ & $669.73 \mathrm{~b}$ & $194.29 \mathrm{~b}$ & $109.85 \mathrm{~b}$ \\
January & $5.67 \mathrm{a}$ & $1.27 \mathrm{a}$ & $22.67 \mathrm{a}$ & $245.18 \mathrm{a}$ & $1063.29 \mathrm{a}$ & $190.95 \mathrm{~b}$ & $240.53 \mathrm{a}$ \\
$F(p)$ & $111.00(<0.001)$ & $128.55(<0.001)$ & $75.22(<0.001)$ & $50.91(<0.001)$ & $71.54(<0.001)$ & $19.82(<0.001)$ & $110.26(<0.001)$ \\
Origin & & & & & & \\
Commercial & 3.26 & 0.68 & $20.77^{\mathrm{a}}$ & $143.32 \mathrm{~b}$ & $466.35 \mathrm{~b}$ & $223.09 \mathrm{~b}$ & $78.9 \mathrm{~b}$ \\
Bolivia & 3.59 & 0.74 & $19.74 \mathrm{~b}$ & $176.77 \mathrm{a}$ & $674.91 \mathrm{a}$ & $282.07 \mathrm{a}$ & $128.18 \mathrm{a}$ \\
$F(p)$ & $1.88(0.174)$ & $1.60(0.285)$ & $7.70(0.007)$ & $5.83(0.018)$ & $18.17(<0.001)$ & $6.89(0.011)$ & $27.30(<0.001)$ \\
Month $x$ Origin $F(p)$ & $6.36(0.001)$ & $3.39(0.023)$ & $3.01(0.035)$ & $1.12(0.347)$ & $3.09(0.033)$ & $2.85(0.043)$ & $8.60(<0.001)$ \\
\hline ANOVA $(\mathrm{p})$ & & & & &
\end{tabular}

ANOVA F $(\mathrm{p})=0.05$. Values followed by different letters in each column and for each factor are significant different according to Tukey test at a $p \leq 0.05 .(\mathrm{n}=3)$
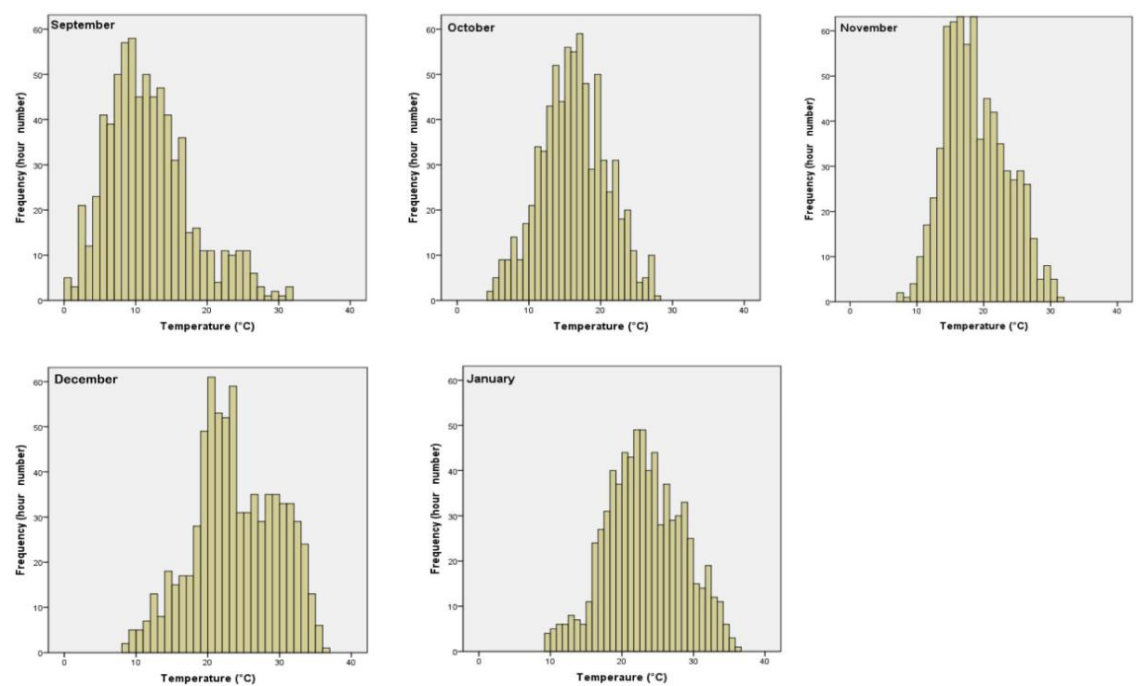

Fig. 1: Hour numbers of mean air temperatures from October to December 2013 and January 2014 registered by the Meteorological Station at the Experimental Field of Morón University

fresh weight reached a minimum on November (15.6\%) to then increase to $22.7 \%$ on January. Leaf area and perimeter as well as leaflet number were maxima on January $\left(245.2 \mathrm{~cm}^{2}, 1063.3 \mathrm{~cm}\right.$ and 240.5 , respectively). However, specific leaf area significantly increased between October and November (220.3 and 403.2 $\left.\mathrm{cm}^{2} / \mathrm{g}\right)$ to then decrease $\left(194.3 \mathrm{~cm}^{2} / \mathrm{g}\right)$ on December, staying constant until January $\left(190.9 \mathrm{~cm}^{2} / \mathrm{g}\right)$.

No significant differences were found on fresh and dry weight of leaf between both origins (Table 1). However, leaf dry weight as percentage of fresh weight, leaf area and perimeter, specific leaf area and leaflet number varied significantly between the two origins (Table 1). Leaf dry weight as percentage of fresh weight was higher on $\mathrm{C}$ leaves (20.8\%) than on B leaves (19.7\%). B leaf area and perimeter were significantly higher $\left(176.8 \mathrm{~cm}^{2}\right.$ and $\left.674.9 \mathrm{~cm}\right)$ than $\mathrm{C}$ leaves $\left(143.3 \mathrm{~cm}^{2}\right.$ and $\left.466.3 \mathrm{~cm}\right)$, while the specific leaf area and leaflet number were $282.1 \mathrm{~cm}^{2} / \mathrm{g}$ and 128.2 for B leaves and $223.1 \mathrm{~cm}^{2} / \mathrm{g}$ and 78.9 for $\mathrm{C}$ leaves, respectively.
Significant interactions were found on the described variables among the studied factors, except for the leaf area (Table 1, Fig. 2A and 2B), due to differential increments in the studied variables, as occurred when comparing leaf fresh and dry weight for both origins, where fresh and dry weight of $\mathrm{C}$ leaves showed a small increase between November and December (growth rates of 0.2 and $1.9 \%$ respectively), while $\mathrm{B}$ leaves presented a higher increase (growth rates of 3.2 and $5.8 \%$, respectively) (Fig. 2A). Specific leaf area increased more significantly between October and November on B leaves than in C leaves, while leaf perimeter increased higher between December and January in $\mathrm{B}$ than in C leaves (Fig. 2B).

Negative and significant correlations were found between the leaf dry weight as percentage of fresh weight and the specific leaf area $(r=-0.828 ; p=<0.001)$.

Antioxidant and phenol contents along the growing season showed significant differences among the months (Table 2). The antioxidant content was maxima on October 
$(8.7 \mathrm{mg} / \mathrm{mL})$, to decline on November to a minimum $(5.5$ $\mathrm{mg} / \mathrm{mL}$ ) and then increase to $7.5-7.6 \mathrm{mg} / \mathrm{mL}$ on December and January. However, if the minimum content of total phenols was observed in November $(7.4 \mathrm{mg} / \mathrm{g}$ dry weight) in coincidence with the antioxidant content, the maximum content was found on December and January $(14.1 \mathrm{mg} / \mathrm{g}$ dry weight).

Antioxidant and phenol content between the two origins were no significant different (Table 2). The antioxidant content was 7.5 and $7.1 \mathrm{mg} / \mathrm{mL}$ for B and C leaves respectively, while the total phenol was 11.1 and $12.0 \mathrm{mg}$ tannic acid equivalents/g dry weight, respectively.

No significant interactions were found on the described variables among the studied factors (Table 2 and Fig. 3), although the phenol content increased significantly between November and December on $\mathrm{C}$ leaves.

The scavenging activity on DPPH radicals along the growing season showed significant differences among the months $(p<0.001)$. The DPPH activity was maximum on October $(56.6 \%)$ to decline on November $(39.4 \%)$ and then increased to 52.8 and $56.3 \%$ on December and January, respectively. The scavenging activity on DPPH radicals of B leaves was significantly higher $(53.0 \%)$ than the obtained for $\mathrm{C}$ leaves (49.4\%). The maximum scavenging activity on DPPH radicals was reached at $0.5 \mathrm{mg} / \mathrm{mL}(92.5 \%)$. Significant interactions were found on the described variables among the studied factors $(p=0.020)$ (Fig. 4A and $4 \mathrm{~B}$ ), due to differential increments in the scavenging activity on DPPH radicals. These interactions can be observed when comparing the scavenging activity on DPPH radicals along the season, where this variable increased markedly between 0.25 and $0.50 \mathrm{mg} / \mathrm{mL}$ on November leaf extracts, and this increment was minima on October and January leaf extract (Fig. 4A). Also, the scavenging activity on DPPH radicals of $\mathrm{C}$ leaves increased higher than $\mathrm{B}$ leaves between 0.25 and $0.50 \mathrm{mg} / \mathrm{mL}$ (Fig. 4B).

Positive and significant correlations were found between the antioxidant and phenol contents $(r=0.441$; $p=0.030)$, the antioxidant content and the scavenging activity on DPPH radicals $(r=0.787 ; p=<0.001)$ and the phenol content and the scavenging activity on DPPH radicals $(r=0.522 ; p=<0.010)$.

\section{Discussion}

The leaf can be considered as a micro copy of the plant (Davi et al., 2008) and the variations on leaf morphology among species, genotypes or ambient conditions can reflect the plant capacity to acquire, use and conserve resources, existing a correlation between leaf morphology and habitat productivity. M. oleifera leaf growth changed along the season and with the growing conditions and therefore according to its phenological phase, as has been cited for the specific leaf area in different species (Lee and Heuvelink, 2003; Atkin et al., 2006).
Table 2: $M$. oleifera leaf composition; Mean values of ANOVA considering the month and the seed origin as main factors, and the content of antioxidant compound $(\mathrm{mg} / \mathrm{ml})$ and total phenol (mg tannic acid equivalents/g DW) as dependent variables

\begin{tabular}{lll}
\hline Main factor & $\begin{array}{l}\text { Antioxidants } \\
(\mathrm{mg} / \mathrm{ml})\end{array}$ & $\begin{array}{l}\text { Total phenols } \\
(\mathrm{mg} / \mathrm{g} \mathrm{DW})\end{array}$ \\
\hline Month & $8.66 \mathrm{a}$ & $10.52 \mathrm{bc}$ \\
October & $5.48 \mathrm{c}$ & $7.40 \mathrm{c}$ \\
November & $7.49 \mathrm{~b}$ & $14.10 \mathrm{ab}$ \\
December & $7.63 \mathrm{~b}$ & $14.15 \mathrm{a}$ \\
January & $45.38(<0.001)$ & $13.26(<0.001)$ \\
$F(p)$ & & \\
& & 11.97 \\
Origin & 7.11 & 11.12 \\
Commercial & 7.51 & $0.90(0.357)$ \\
Bolivia & $4.09(0.060)$ & $1.56(0.238)$ \\
$F(p)$ & $0.91(0.459)$ & \\
Interaction Month $x$ Origin $F(p)$ & ANOVA F $(\mathrm{p})=0.05$. Values followed by different letters in each column \\
and for each factor are significant different according to Tukey test at a $p \leq$ \\
0.05. $(\mathrm{n}=3)$
\end{tabular}
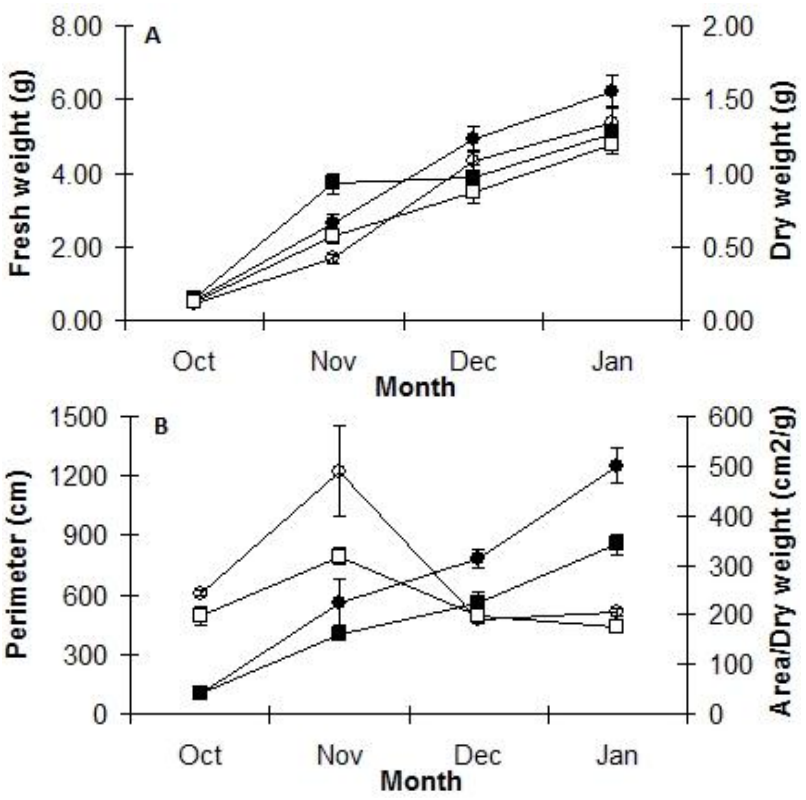

Fig. 2: Leaf growth of $M$. oleifera along the growing season. A. • Fresh leaf weight of Bolivia origin; a Fresh leaf weight of Commercial origin; $O$ Dry leaf weight of Bolivia origin; $\square$ Dry leaf weight of Commercial origin. B. - Leaf perimeter of Bolivia origin; - Leaf perimeter of Commercial origin; $\bigcirc$ Specific leaf area of Bolivia origin; $\square$ Specific leaf area of Commercial origin. Bars represent \pm 1 standard error of the mean

Leaf growth pattern of $\mathrm{C}$ origin particularly analyzed through the fresh weight, the perimeter and the area showed a double sigmoid curve, with a first period of fast growth between October and November, followed by a lag period until December, to then increase till the end of the experiment. However, B leaf growth only showed a lag 
period through the leaf area. The behavior of the leaf growth of $\mathrm{C}$ origin could be influenced by the climatic conditions due to when analyzing the mean air temperatures for October and November, it has increased from 16.2 to $18.8^{\circ} \mathrm{C}$, being perhaps a small temperature increment for $\mathrm{C}$ leaf growth. The specific leaf area reached a maximum value on November due to a differential increment between both variables, area and dry weight; while leaf area increased 7.3 times between October and November for both origins, the increase in the leaf dry weight was 4.7 and 6.5 times for $\mathrm{B}$ and $\mathrm{C}$ leaves, respectively. The specific leaf area of $\mathrm{B}$ and $\mathrm{C}$ origins were higher (6.6 to 19.9 times) than the reported by Muhl et al. (2011) for plants obtained from wild $M$. oleifera seeds from Africa growing under controlled conditions, while leaf area was also positively correlated with tree height and stem thickening growth rates (Muhl, 2009).

The antioxidant and phenol contents for $\mathrm{C}$ and $\mathrm{B}$ leaves presented a highlighted minimum on November, in coincidence with the decrease of the leaf dry weight as percentage of fresh weight and the increase of the specific leaf area. Also, the scavenging activity on DPPH radicals on leaf extracts of November was minima for both origins. Changes in the contents of leaf secondary metabolites with the phenology along the growing season have been described for Eucalyptus sp. (Macauley and Fox, 2006), Coffea sp. (Salgado et al., 2008) and Artemisia and Hypericum sp. (Rugna et al., 2013), among others.

Positive and significant correlations were found between the leaf dry weight as percentage of fresh weight with the antioxidant content $(r=0.764 ; p<0.001)$, with the phenol content $(r=0.753 ; p<0.001)$ and DPPH activity $(r=0.726 ; p<0.001)$. However, negative and significant correlations were found between the specific leaf area with the antioxidant content $(r=-0.662 ; p<0.001)$, with the phenol content $(r=-0.588 ; p=0.002)$ and DPPH activity $(r=-0.723 ; p<0.001)$. The described correlations could explain the fact that $\mathrm{B}$ leaves presented a higher specific leaf area and growth rates than $\mathrm{C}$ leaves, and a lower dry weight as percentage of fresh weight and phenol content than $\mathrm{C}$ leaves, in coincidence with the correlations cited by Poorter and de Jong (1999) in several species. The lower leaf dry weight as percentage of fresh weight, higher specific leaf area, higher relative growth rate and lower phenol content on B leaves than C leaves could indicate that B plants are geared for a higher productivity rate of resource acquisition than $\mathrm{C}$ plants. These concepts can be confirmed with the fact that the $\mathrm{C}$ plants produced a larger number of flower buds respect of those of B plants (Salinas, 2013) probably due to larger amount of accumulated reserves.

$\mathrm{C}$ and B leaf phenol content (11.1 to $12.0 \mathrm{mg} / \mathrm{g}$ dry weight) was higher than the reported by Luqman et al. (2012) $(22 \mu \mathrm{g} / \mathrm{mL})$, and Nouman et al. (2016) $(0.5 \mu \mathrm{g} / \mathrm{g}$ dry weight), although lower than the reporter by Muhammad $e t$ al. (2013) (7.4 g 100/g dry weight). The obtained

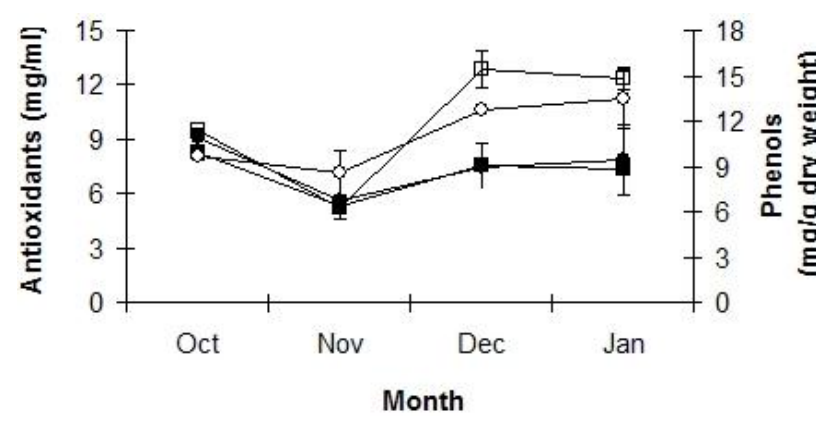

Fig. 3: Leaf composition of $M$. oleifera along the growing season. - Antioxidant content of Bolivia (B) origin; Antioxidant content of Commercial (C) origin; ○ Phenol content (tannic acid equivalents) of Bolivia (B) origin; $\square$ Phenol content (tannic acid equivalents) of Commercial (C) origin. Bars represent \pm 1 standard error of the mean
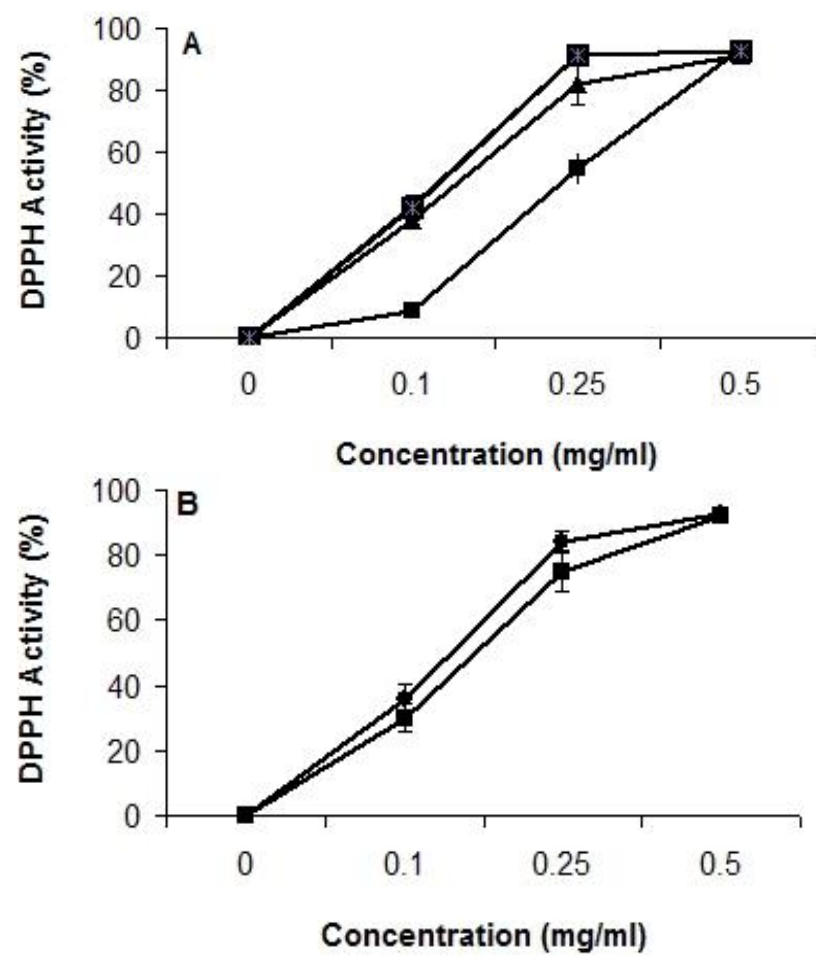

Fig. 4: Scavenging activity of the leaf methanolic extracts of $M$. oleifera on DPPH radicals at different concentrations. A. $\circ$ October; - November; $\boldsymbol{\Delta}$ December; $\mathrm{x}$ January. B. • Bolivia (B) origin, C Commercial (C) origin. Bars represent \pm 1 standard error of the mean

scavenging activity on DPPH radicals on leaf extracts was higher than that referred by Siddhuraju and Becker (2003) and Luqman et al. (2012) on M. oleifera leaves and comparable with the obtained for fruits extracts. Positive correlations between phenol content and DPPH activity was also found for M. oleifera by Nouman et al. (2016).

Plants alter their physiology, morphology and 
development in response to environmental changes (Guo et al., 2007). The correlations among changes in leaf morphology and composition with the phenology and environment are useful tools for the understanding of plant plasticity to seasonal changes in their biotic and abiotic environment, or when plants are collected for therapeutic aims or to perform chemotaxonomic studies (Rugna et al., 2013).

M. oleifera trees are mainly found throughout the tropics around the world, and the successful cultivation of this species in cooler climates would greatly increase their production areas (Muh et al., 2011). Growth of M. oleifera plants is possible in the experimental field of Morón University (near Moreno city), with a mean temperature during the period of study of $20.5^{\circ} \mathrm{C}$, and this fact allow to preliminary consider this agro climatic zone as one of the southernmost area for $M$. oleifera culture in coincidence with that cited by Falasca and Bernabé (2008).

\section{Conclusion}

The study of the changes of the leaf growth and antioxidant content of M. oleifera (B and $\mathrm{C}$ origins) along the growing season in Buenos Aires, Argentina, are the first antecedents, allowing to preliminary consider this area as one of the southernmost zone for M. oleifera growth. Specific leaf area, leaf dry weight as percentage of fresh weight, phenol content and activity of DPPH radicals on leaf extracts were significantly correlated, which could be used on productivity estimation and nutraceutical valuation. The phenol content and activity of DPPH radicals on leaf extracts of B and C origins indicate that the leaves of the plants growing in the described conditions are of noteworthy value.

\section{Acknowledgments}

We thank to Sergio Elio Aguero and Alfredo Omar Medina for his technical support and to Eng Marta Alonso for her collaboration.

\section{References}

Anwar, F., S. Nahid Zafar and U. Rashid, 2006. Characterization of Moringa oleifera seed oil from drought and irrigated regions of Punjab, Pakistan. Grasas y Aceites, 57: 160-168

Arena, M.E., P. Postemsky and N Curvetto, 2012. Accumulation patterns of phenolic compounds during fruit growth and ripening of Berberis buxifolia, a native Patagonian species. New Zeal. J. Bot., 50: 15-28

Arora, D.S., J.G. Onsare and H. Kaur, 2013. Bioprospecting of Moringa (Moringaceae): microbiological perspective. J. Pharmac. Phytochem., 1: $193-215$

Atawodi, S.E., J.C. Atawodi, G.A. Idakwo, B. Pfundstein, R. Haubner, G. Wurtele and R.W. Owen, 2010. Evaluation of the polyphenol content and antioxidant properties of methanol extracts of the leaves, stem and root barks of Moringa oleifera Lam. J. Med. Food, 13: $710-716$

Atkin, O.K., B.R. Loveys, L.J. Atkinson and T.L. Pons, 2006. Phenotypic plasticity and growth temperature: understanding interspecific variability. J. Exp. Bot., 57: 267-81
Basra, S.M.A., W. Nouman, H.U. Rehman, M. Usman and Z.H. Nazli, 2015. Biomass production and nutritional composition of Moringa oleifera under different cutting frequencies and planting spacings. Int. J. Agric. Biol., 17: 1055-1060

Davi, H., C. Barbaroux, E. Dufrêne, C. François, P. Montpied, N. Bréda and F. Badeck, 2008. Modelling leaf mass per area in forest canopy as affected by prevailing radiation conditions. Ecol. Model., 211: 339-349

Delaveau, P. and P. Boiteau, 1980: Huiles a interêt pharmacologique, cosmetologique et dietetique. 4. Huiles de Moringa oleifera Lamk. et de M. drouhardii Jumelle. Plantes Med. Phytother., 14: 29-33

Dhanalakshmi, R., S. Umamaheswari, P. Sugandhi and D.A. Prasanth, 2013. Biodiversity of the endophytic fungi isolated from Moringa oleifera of Yercaud Hills. Int. J. Pharm. Sci. Res., 4: 1064-1068

Falasca, S. and M.A. Bernabé, 2008. Potenciales usos y delimitación del área de cultivo de Moringa oleifera en la Argentina. Revista virtual de REDESMA, pp: $1-16$

Ganatra Tejas, H., H. Joshi Umang, N. Bhalodia Payal and R. Desai Tusharbindu, 2012. A panoramic view on pharmacocnostic, pharmacological, nutritional, therapeutic and prophylactic value of Moringa oleifera Lam. Int. Res. J. Pharm., 3: 1-7

Guo, W.H., B. Li, X.S. Zhang and R. Wang, 2007. Architectural plasticity and growth responses of Hippophae rhamnoides and Caragana intermedia seedlings to simulated water stress. J. Arid. Environ., 69: 385-399

Lee, J.H. and E. Heuvelink, 2003. Simulation of leaf area development based on dry matter partitioning and specific leaf area for cut chrysanthemum. Ann. Bot., 91: 319-327

Leone, A., A. Spada, A. Battezzati, J. and S. Bertoli, 2015a. Cultivation, genetic, ethnopharmacology, phytochemistry and pharmacology of Moringa oleifera leaves: An overview. Int. J. Mol. Sci., 16: 1279112835

Leone, A., G. Fiorillo, F. Criscuoli, S. Filippini and S. Bertoli, $2015 \mathrm{~b}$. Nutritional characterization and phenolic profiling of Moringa oleifera leaves grown in chad, sahrawi refugee camps, and Haiti. Int. J. Mol. Sci., 16: 18923-18937

Luqman, S., S. Srivastava, R. Kumar, A. Kumar Maurya and D. Chanda, 2012. Experimental Assessment of Moringa oleifera Leaf and Fruit for Its Antistress, Antioxidant and Scavenging Potential Using In Vitro and In Vivo Assays. Evidence-Based Complementary and Alternative Medicine, doi:10.1155/2012/519084

Macauley, B. and L.R. Fox, 2006. Variation in total phenols and condensed tannins in Eucalyptus: Leaf phenology and insect grazing. Austr. J. Ecol., 5: 31-35

Makkar,H.P.S., M. Bluemmel, N.K. Borowy and K. Becker, 1993. Gravimetric determination of tannins and their correlations with chemical and protein precipitation methods. J. Sci. Food Agric., 61: 161-165

Muhammad, A.A., N.A. Syarina Pauzi, P. Arulselvan, F. Abas and S. Fakurazi, 2013. In Vitro Wound Healing Potential and Identification of Bioactive Compounds from Moringa oleifera Lam. Bio Med. Res. Int., doi: $10.1155 / 2013 / 974580$

Muhl, Q.E., 2009. Seed germination, tree growth and flowering responses of Moringa oleifera Lam. (Horseradicsh tree) to temperature. MSc Thesis, p: 127. University of Pretoria

Muhl, Q.E., E.S. Du Toit and P.J. Robbertse, 2011. Moringa oleifera (horseradish tree) leaf adaptation to temperature regimes. Int. J. Agric. Biol., 13: 1021-1024

Nair, A.G.R. and S. Sankaras, 1962. Pigments of flowers from Moringa pterygosperma. Curr. Sci., 31: 155

Nouman, W., F. Anwar, T. Gull, A. Newton, E. Rosa and R. DomínguezPerles, 2016. Profiling of polyphenolics, nutrients and antioxidant potential of germoplasm's leaves from seven cultivars of Moringa oleifera Lam. Ind. Crops Prod., 83: 166-176

Palafox, J., A. Navarrete, J. Sacramento-Rivero, C. Rubio-Atoche, P. Escoffie and J. Rocha-Uribe, 2012. Extraction and Characterization of Oil from Moringa oleifera Using Supercritical $\mathrm{CO}_{2}$ and Traditional Solvents. Amer. J. Anal. Chem., 3: 946-949

Parrotta, J.A., 1993. Moringa oleifera Lam: Resedá, Horseradish Tree, Moringaceae, Horseradish-tree Family. International Institute of Tropical Forestry, US Department of Agriculture, Forest Service, USA 
Poorter, H. and R. de Jong, 1999. A comparison of specific leaf area, chemical composition and leaf construction costs of field plants from 15 habitats differing in productivity. New Phytol., 143: 163-176

Rashid, U., F. Anwar, B.R. Moser and G. Knothe, 2008. Moringa oleifera oil: a possible source of biodesel. Bioresour. Technol., 99: 8177-8179

Rugna, A.Z., A.A. Gurni and M.L. Wagner, 2013. Phenological variations of polyphenols in Smilax campestris (Smilaceae). Turk. J. Bot., 37: 350354

Salgado, P.R., J.L. Favarin, R.A. Leandro and O.F. Lima Filho, 2008. Total phenol concentrations in coffee tree leaves during fruit development. Sci. Agric., 65: 354-359

Salinas, M., 2013. Estudio del crecimiento y reproducción de Moringa oleifera Lam en la Provincia de Buenos Aires. Facultad de Agronomía y Cs Agroalimentarias. UM Thesis, p: 41

Sankhalkar, S. and V. Vernekar, 2016. Quantitative and Qualitative analysis of Phenolic and Flavonoid content in Moringa oleifera Lam and Ocimum tenuiflorum L. Pharmacogn. Res., 8: 16-21

Shimada, K., K. Fujikawa, K. Yahara and T. Nakamura, 1992 Antioxidative properties of Xanthan on the autoxidation of soybean oil in cyclodextrin emulsion. J. Agric. Food Chem., 6: 945-948
Siddhuraju, P. and K. Becker, 2003. Antioxidant Properties of Various Solvent Extracts of Total Phenolic Constituents from Three Different Agroclimatic Origins of Drumstick Tree (Moringa oleifera Lam.) Leaves. J. Agric. Food Chem., 51: 2144-2155

Singh, G.P., R. Garg, S. Bhardwaj and S.K: Sharma, 2012. Anti-inflamatory evaluation of leaf extract of Moringa oleifera. J. Pharmac. Sci. Innovation, 1: 22-24

Tende, J.A., I. Ezekiel, A.A.U. Dikko and A.D.T. Goji, 2011. Effect of ethanolic leaves extract of Moringa oleifera on blood glucose levels of streptozocin-induced diabetics and normoglycemic Wistar rats. Brit. J. Pharm. Toxic., 2: 1-4

Yameogo, C.W., M.D. Bengaly, A. Savadogo, P.A. Nikiema and S.A Traore, 2011. Determination of chemical composition and nutritional values of Moringa oleifera leaves. Pak. J. Nut., 10: 264-268

(Received 02 September 2015; Accepted 05 February 2016) 